\title{
Response of a DIN 18MnCrSiMo6-4 Continuous Cooling Bainitic Steel to Different Plasma Nitriding Gas Mixtures
}

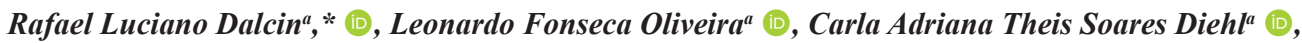 \\ Alexandre da Silva Rocha ${ }^{a}$
}

${ }^{a}$ Universidade Federal do Rio Grande do Sul-UFRGS, Programa de Pós-Graduação em Engenharia de Minas, Metalúrgica e de Materiais - PPGE3M, Laboratório de Transformação Mecânica - LdTM, Porto Alegre, RS, Brasil.

Received: June 21, 2020; Revised: August 07, 2020; Accepted: August 25, 2020

\begin{abstract}
Continuous cooling bainitic steels has been widely used in industrial processes owing to its excellent mechanical properties and toughness. Although the surface properties of them are acceptable for many purposes, for their use in mechanical components like gears, it is necessary to improve their surface properties. Plasma nitriding treatments was carried out of a DIN $18 \mathrm{MnCrSiMo6}-4$ steel at $500{ }^{\circ} \mathrm{C}$, with three different nitrogen gas composition: 76,24 and 5 vol.\% nitrogen in hydrogen, for 3, 6 and 9 hours. The surfaces were characterized concerning the microstructure, microhardness, fracture toughness, nitrogen concentration and carbon composition, phase composition and residual stress states. Based on the results presented, layer growth constants $(k)$ for different nitrogen gas composition was determined. The carbon profiles of samples indicate that there was decarburization during the plasma nitriding. The nitrided samples with thicker compound layers presented a fracture behavior dominated by the formation of Palmqvist cracks. X-ray phase analysis indicated the formation of biphasic compound layer on the surface of all nitrided samples with 76 and 24 vol. $\%$ nitrogen, while the nitrided samples with 5 vol.\% nitrogen indicated the formation of monophasic compound layer. The diffusion zone presented compressive residual stresses with highest values near the surface.
\end{abstract}

Keywords: DIN 18MnCrSiMo6-4 Steel, Plasma Nitriding, Layer Growth Constant, Fracture Toughness, Phase Composition and Residual Stress Analysis.

\section{Introduction}

In general, the nitriding process develops metallurgical chemical reactions on the surface of the treated steel, leading to the formation of a nitrogen compound layer, consisting of $\varepsilon-\mathrm{Fe}_{2-3} \mathrm{~N}$ and $\gamma^{\prime}-\mathrm{Fe}_{4} \mathrm{~N}$ nitrides ${ }^{1,2}$. With the progressive diffusion of nitrogen, a nitriding diffusion zone is formed, consisting of a region hardened by the fine and homogeneous precipitation of iron and/or alloy nitrides, and nitrogen-saturated ferrite. In the diffusion zone (carbo) nitriding precipitation in grain boundaries can occur, which leads to decrease in surface toughness ${ }^{3}$. In the plasma nitriding treatment, it is possible to control treatment parameters such as the composition of the gas mixture, the temperature and the nitriding time in order to tailor the properties achieved by treatment. These parameters must be precisely controlled to develop good surface hardness, toughness and even avoid the formation of the detrimental compound layer features ${ }^{4-6}$.

The composition and thickness of the nitrided layers strongly depends on the steel composition. For example, high alloy steels exhibit high hardness due to dispersed alloy nitrides in the matrix and high surface residual stresses are

*e-mail: rafael.dalcin@ufrgs.br generated in the compound layer and diffusion zone for these steels, which are the result of chemical composition gradients, stress fields around precipitates, volume changes and thermal effects 7 . In the case of low alloy steels, the diffusion zone does not reach hardness values as high as the obtained when nitriding tool steels, for example ${ }^{6,8}$. For low alloy steels, the compound layer plays the most important role against wear, and the diffusion zone has a secondary role, therefore it is important to develop the correct morphology and phase composition of the compound layer ${ }^{8}$.

Recent developments of direct heat-treated steels for high strength forgings have led to some new steel grades with excellent service properties ${ }^{9-12}$. The combination of multiphase microstructures with surface hardening treatments in steel opens new possibilities, by allowing high levels of strength and ductility to be adjusted ${ }^{13-15}$. The major influence on the metallurgical properties of plasma nitrided low alloy steels is played by the gas mixture, temperature and treatment time ${ }^{8,16}$. Therefore, the objective of the present work is to evaluate the response of a DIN $18 \mathrm{MnCrSiMo6}-4$ continuous cooling bainitic steel to plasma nitriding with different combinations of time and nitrogen gas composition. 


\section{Materials and Methods}

\subsection{Material under investigation and plasma nitriding}

Plasma nitriding treatments were carried out in a plasma nitriding apparatus equipped with a DC power supply which was developed in the Metallurgy Department of Federal University of Rio Grande do Sul (UFRGS). The plasma nitriding apparatus, with approximately 212 liters of internal volume, is equipped with an ALCATEL Vacuum Pump double-stage mechanical pump with a pumping speed of $27 \mathrm{~m}^{3} / \mathrm{h}$, system supply and measurement of gas flow through the use of mass flow meters controlled by the MKS Type $247 D$ module. The internal pressure control is performed by an MKS 600 Series Pressure Controller system, which controls the outflow to the pump through the angular positioning of a butterfly valve. The system is fed back with a BARATRON electronic pressure gauge. The power source used for the nitriding of the samples uses $120 \mathrm{~Hz}$ frequency, with a negative pole coupled to the treatment base and the positive pole to the (grounded) frame. The apparatus also has an inspection window that allows the visualization of the plasma formation, and a series of passers are used for the passage of power, thermocouples and gases. Instrumentation involves measuring voltage, current, pulse display, frequency measurement and temperature measurement.

For plasma nitriding, samples were disks with $10 \mathrm{~mm}$ of height and $43.2 \mathrm{~mm}$ of diameter manufactured from cylindrical bars of a continuous cooling bainitic steel DIN 18MnCrSiMo6-4. The material's chemical composition, microstructure and mechanical properties are shown in previous work ${ }^{16}$. Prior to the surface treatments, samples flat faces were ground with silicon carbide grinding paper in a sequence with increasing mesh (\#100, \#220, \#320, \#400, $\# 600$, \#1200) and then polished with diamond paste with an abrasive size of $3 \mu \mathrm{m}$ in order to obtain low roughness, almost no plastic deformation and consequently low initial residual stresses in the surface. The samples were degreased and cleaned with acetone in an ultrasonic bath before being placed into the furnace. After cleaning, the specimens were heated and sputter cleaned in plasma.

The present work is a continuation of previous work entitled "Response of a DIN 18MnCrSiMo6-4 Continuous Cooling Bainitic Steel to Plasma Nitriding with a Nitrogen Rich Gas Composition"16. For the investigated treatment conditions it was found that the treatment temperature of
$500{ }^{\circ} \mathrm{C}$ developed the best results; therefore, in this work we opted to use this temperature.

Table 1 summarizes the different plasma nitriding runs. In the present work, three different gas mixtures were used for the treatments: 5, 24 and $76 \mathrm{vol}$.\% nitrogen $\left(\mathrm{N}_{2}\right)$ in hydrogen $\left(\mathrm{H}_{2}\right)$, keeping the temperature of the samples at $500{ }^{\circ} \mathrm{C}$ during the nitriding step for different treatment times of 3, 6 and 9 hours. Voltage as well pressure are adjusted to reach the treatment temperature. Since the chamber worked in cold wall mode (i.e. no auxiliary heating system was used) the heating of samples was directly dependent on the ion bombardment. For example, plasma nitriding in an atmosphere containing more hydrogen, requires applications of greater potential differences, since hydrogen atom mass is lower causing a small linear moment than nitrogen ${ }^{17}$. As a consequence, also the pressure has to be adjusted for compensation, leading to the choice of a higher pressure in the treatments with gas mixture containing 5 vol. $\% \mathrm{~N}_{2}\left(95 \mathrm{vol} . \% \mathrm{H}_{2}\right)$ than for the other gas compositions.

\subsection{Samples characterization}

\subsubsection{Microstructural analysis and compound layer thickness measurements}

For the microstructural analysis of the nitrided layers, samples were carefully cut in a precision diamond blade cutting machine and mounted in bakelite using a metallic support on the nitrided surface to promote edge retention. After mounting, the cross-sections were ground with silicon grinding paper in a sequence with increasing mesh (\#100,\#220,\#320,\#400,\#600,\#1200) and polished with a diamond paste of $3 \mu \mathrm{m}$ grain size. A Nital 3\% solution was used to etch the samples revealing the microstructure of the nitrided layers. The cross-sectional microstructural images were obtained in an OLYMPUS BX51M optical microscope. The compound layer thicknesses were measured using the software IMAGE $J^{T M}$.

\subsubsection{Surface hardness and case depth measurements}

After plasma nitriding, surface Vickers microhardness measurements of the face of the nitrided sample and Vickers microhardness profiles of the cross-sections were obtained with an INSIZE ISH-TDV 1000 microhardness tester. Five microhardness profiles were constructed by Vickers microhardness testing, using a load of $100 \mathrm{gf}$ with an application time of $10 \mathrm{~s}^{18}$. The determination of the nitrided layer depth was carried out based on

Table 1. Parameters used for plasma nitriding of samples using three different nitrogen gas composition.

\begin{tabular}{ccccc}
\hline Nitriding time (h) & Temperature $\left({ }^{\circ} \mathbf{C}\right)$ & Gas mixtures $\left(\right.$ vol. $\% \mathbf{~ N}_{\mathbf{2}}$ in $\left.\mathbf{H}_{2}\right)$ & $\begin{array}{c}\text { Power, rms } \\
(\mathbf{k V A})\end{array}$ & Chamber pressure $($ Pa) \\
\hline 3 & 500 & 76 vol. $\% \mathrm{~N}_{2}$ in 24 vol. $\% \mathrm{H}_{2}$ & 1.0 & 300 \\
\hline 6 & 500 & 76 vol. $\% \mathrm{~N}_{2}$ in 24 vol. $\% \mathrm{H}_{2}$ & 1.1 & 300 \\
\hline 9 & 500 & 76 vol. $\% \mathrm{~N}_{2}$ in 24 vol. $\% \mathrm{H}_{2}$ & 1.1 & 300 \\
\hline 3 & 500 & 24 vol. $\% \mathrm{~N}_{2}$ in 76 vol. $\% \mathrm{H}_{2}$ & 1.0 & 300 \\
\hline 6 & 500 & 24 vol. $\% \mathrm{~N}_{2}$ in 76 vol. $\% \mathrm{H}_{2}$ & 1.0 & 300 \\
\hline 9 & 500 & 24 vol. $\% \mathrm{~N}_{2}$ in 76 vol. $\% \mathrm{H}_{2}$ & 1.1 & 400 \\
\hline 3 & 500 & 5 vol. $\% \mathrm{~N}_{2}$ in 95 vol. $\% \mathrm{H}_{2}$ & 0.9 & 400 \\
\hline 6 & 500 & 5 vol. $\% \mathrm{~N}_{2}$ in 95 vol. $\% \mathrm{H}_{2}$ & 1.1 & 400 \\
\hline 9 & 500 & 5 vol. $\% \mathrm{~N}_{2}$ in 95 vol. $\% \mathrm{H}_{2}$ & 1.3 &
\end{tabular}


the microhardness profiles and following the recommendations established in DIN $50190^{19}$. Therefore, the end of the nitrided layer (compound layer + diffusion zone) was conventionally determined by the position where hardness measurements are $50 \mathrm{HV}$ above core hardness.

\subsubsection{Glow discharge optical emission spectrometry (GDOES) analysis}

Nitrogen concentration depth profiles and the carbon composition from the bainitic steel surface were obtained by means of GDOES after plasma nitriding. Determination of chemical composition were carried out using a LECO GDS 750 A spectrometer of Stiftung Institut für Werkstofftechnik (IWT) from Bremen (Germany). For atomization and excitation, the Ar-ions in a glow discharge source are accelerated within a hollow anode to the sample surface (cathode) and cause the sputtering of sample atoms. These pass back into the plasma where they are excited and afterwards emit light whit wavelengths in the optical range which are characteristic for each element. For spectral decomposing and intensity measurement, the emitted light passes the entrance slit into the spectrometer and is decomposed by a refracting grating according to wavelength. The emission lines are focused onto photomultiplier detector located on the Rowland circle, one for each element. So, the intensities of all lines are measured simultaneously ( 2 circles, 48 channels, $\lambda=130-750 \mathrm{~nm}$ ).

\subsubsection{Fracture toughness evaluation from vickers indentation}

In order to determine the fracture toughness of the nitrided layer, the analysis model proposed by Nolan et al. ${ }^{5}$ was applied. This method was chosen because the Vickers pyramid indenter has edges at $90^{\circ}$ to induce the formation of measurable Palmqvist cracks. This method rely on the shape of the cracks developed by the hardness indenter. Fracture toughness $\left(\mathrm{K}_{\mathrm{IC}}\right)$ is estimated by visualizing and measuring cracks formed around hardness test indentations. Nitrided samples were slightly polished using $3 \mu \mathrm{m}$ diamond paste for 20 seconds, then in a Vickers hardness test indentations on samples nitride faces were carried out with increasing loads $(1,5,10,20,30$ and $50 \mathrm{kgf})$. The minimum load necessary to generate an observable Palmqvist crack on the surface was recorded for each tested sample.

The crack length was measured under an optical microscope, and the average values of Vickers indentation diagonals length and cracks length were used to calculate the $\mathrm{K}_{\mathrm{IC}}$, according to the simplified relationship developed by Shetty et al..$^{20}$, as given in Equation 1 . The relation is valid for valid for the Palmqvist crack mode. $l$ is the mean length of the crack, $a$ is the mean length of the indentation diagonals and $P$ is the applied load on the test.

$$
K_{I C}=0.0319\left(\frac{P}{a \sqrt{l}}\right)
$$

It has been suggested that the Equation will give an estimate of the crack arrest fracture toughness $\left(\mathrm{K}_{\mathrm{IC}}\right)$. According to the Palmqvist theory, fracture toughness $\left(\mathrm{K}_{\mathrm{IC}}\right)$ should be independent of the applied load. The most valid measure of $\mathrm{K}_{\mathrm{IC}}$ for the thin coating can therefore be obtained by extrapolating the $\mathrm{K}_{\mathrm{IC}}$ versus $\mathrm{P}$ data to $\mathrm{P}=0$, where the intrinsic fracture toughness of the coating, denoted by $\mathrm{K}_{\mathrm{IC} 0}$, can be derived ${ }^{5}$.

\subsubsection{Phase and residual stress analysis by $x$-ray diffraction}

Phase and residual stress X-ray diffraction were carried out using a GE SEIFERT CHARON XRD M-RESEARCH $E D I T I O N$ diffractometer equipped with a METEOR $1 D$ fast line position sensitive detector. Phase analysis was performed on samples surface in the Bragg-Brentano geometry condition $(\theta-2 \theta)$ with $\mathrm{Cr}-\mathrm{K} \alpha(\lambda=2.2897 \AA)$ radiation. Diffraction lines were recorded in the range of $2 \theta$ from $50^{\circ}$ to $166^{\circ}$, with $0.01^{\circ}$ spacing and a scan time of $200 \mathrm{~s}$ for each step. Residual stresses were determined at three different positions on the samples faces by using a $\psi$-diffractometer with $\mathrm{Cr}-\mathrm{K \alpha}$ radiation. For strain determination the $\{211\}$ diffraction lines of $\alpha$-iron were recorded at $15 \psi$ inclinations in the range of $-60^{\circ}$ to $+60^{\circ}$. The $\sin ^{2} \psi$ method with macroscopic elastic constants of steel, $E=210.000 \mathrm{MPa}$ and $v=0.28$, was used for residual stress calculations. The penetration depth of $C r-K \alpha$ radiation in the $\alpha$-iron allowed measurements in the diffusion zone, even with a small layer at the surface ${ }^{1}$.

In order to obtain residual stress profiles of the samples near surface, before each measurement a depth layer removal was carried out by electrolytic etching. During the layer removal process, the samples were dipped into a solution containing $24.19 \%$ distilled water mixed with $33.87 \%$ sulfuric acid $\left(\mathrm{H}_{2} \mathrm{SO}_{4}\right)$ and $41.94 \%$ phosphoric acid $\left(\mathrm{H}_{3} \mathrm{PO}_{4}\right)$, a magnetic stirrer to mix the solution was used during all process. Sample was connected to the anode and the stainless steel basket, which contained the electrolytic solution, was connected to the cathode. A ddp of $10 \mathrm{~V}$ was applied giving a current of about $10 \mathrm{~A}$ during the removal process. Sample thickness was measured before and after a pre-set attack time using a micrometer. The estimated depth measurement error was $\pm 1 \mu \mathrm{m}$. About eight removals with successive measurements were carried out for each sample.

\section{Results and Discussion}

\subsection{Phase analysis}

Figures 1a-c shows the diffractograms of samples plasma nitrided with the three different nitrogen gas mixtures and a non-nitrided sample (as a reference). The sample of the non-nitrided steel is characterized by the presence of the $\alpha$-Iron peaks in positions $68.8^{\circ} ; 106.1^{\circ}$ and $156.3^{\circ}$. According to Gong et al. ${ }^{21}$, the broadening of the peak, indicates the presence of bainite/martensite. For all the nitriding conditions peaks of the main nitrides are seen that indicates the formation of the compound layer. In the diffraction patterns, Figures $1 \mathrm{a}, \mathrm{b}$, the $\varepsilon-\mathrm{Fe}_{2-3}(\mathrm{C}) \mathrm{N}$ is detected as the main phase, for the diffraction in the positions: $58.2^{\circ} ; 62.9^{\circ} ; 67.0^{\circ} ; 91.0^{\circ}$; $114.8^{\circ} ; 134.3^{\circ} ; 153.2^{\circ}$ and $164.5^{\circ}$, and there is also evidence for the formation of the $\gamma^{\prime}-\mathrm{Fe}_{4} \mathrm{~N}$ nitride phase by the peaks at the positions: $63.1^{\circ} ; 74.3^{\circ}$ and $117.4^{\circ}$, Figures $1 \mathrm{a}-\mathrm{c}$. The intensity of the peaks of the $\alpha$-iron decreases with the increase of the thickness of the compound layer thickness, while the $\varepsilon-\mathrm{Fe}_{2-3}(\mathrm{C}) \mathrm{N}$ and $\gamma^{\prime}-\mathrm{Fe}_{4} \mathrm{~N}$ phase peaks intensity increase. This happens due to the absorption of the radiation by the 


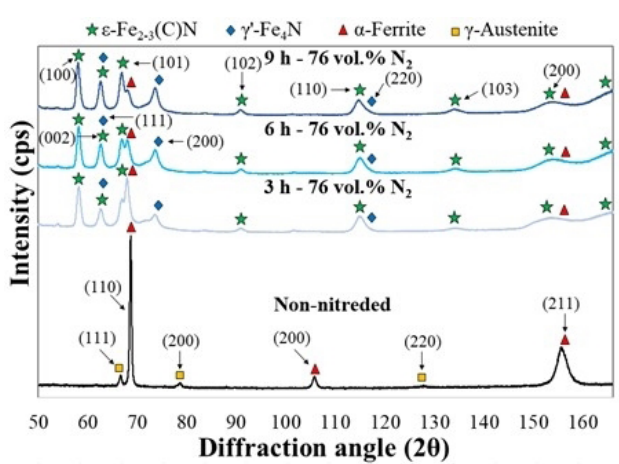

(a)

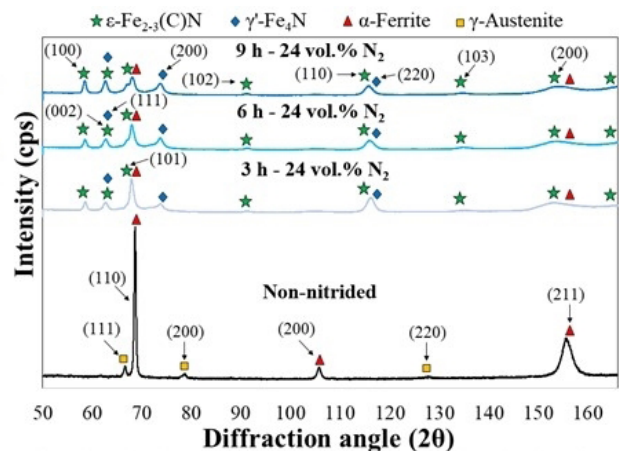

(b)

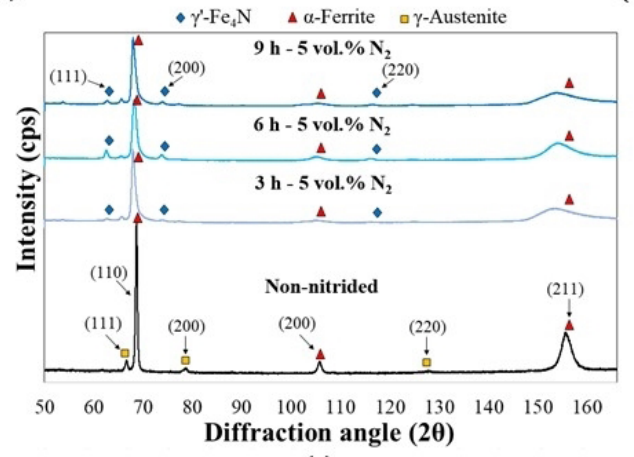

(c)

Figure 1. X-ray diffractograms of non-nitrided sample and plasma nitrided samples for (a) 76 vol. $\% \mathrm{~N}_{2}$, (b) 24 vol. $\% \mathrm{~N}_{2}$ and (c) 5 vol. $\% \mathrm{~N}_{2}$.

most superficial portions of the material and, therefore, the diffraction intensity weakens.

Both nitriding conditions, with high concentrations of nitrogen $\left(76 \mathrm{vol} . \% \mathrm{~N}_{2}\right)$ and with intermediate nitrogen content $\left(24\right.$ vol. $\left.\% \mathrm{~N}_{2}\right)$, have invariably generated the characteristic phases $\varepsilon-\mathrm{Fe}_{2-3}(\mathrm{C}) \mathrm{N}$ and $\gamma^{\prime}-\mathrm{Fe}_{4} \mathrm{~N}$, with a preponderance of $\varepsilon-\mathrm{Fe}_{2-3}(\mathrm{C}) \mathrm{N}$ content for the 76 vol. $\% \mathrm{~N}_{2}$ condition and more $\gamma^{\prime}-\mathrm{Fe}_{4} \mathrm{~N}$ for 24 vol. $\% \mathrm{~N}_{2}$ condition, Figures $1 \mathrm{a}, \mathrm{b}$. It is well known from the literature that biphasic compound layers have worse properties than monophasic layers due to the different thermal expansion coefficients of the main nitrides, which leads to a more brittle layer ${ }^{22-24}$. Therefore, a monophasic layer is preferred, having the $\varepsilon-\mathrm{Fe}_{2-3}(\mathrm{C}) \mathrm{N}$ layer higher abrasion resistance than $\gamma^{\prime}-\mathrm{Fe}_{4} \mathrm{~N}$, but comparatively more brittle.

These results show that intermediate gas mixtures with concentrations above 24 vol. $\% \mathrm{~N}_{2}$ did not promote the formation of a monophasic $\gamma^{\prime}-\mathrm{Fe}_{4} \mathrm{~N}$ compound layer. However, Corengia et al. ${ }^{25}$ concluded that the $\gamma^{\prime}-\mathrm{Fe}_{4} \mathrm{~N}$ monophasic appears for the AISI 4140 steel (also using $500{ }^{\circ} \mathrm{C}$ and 24 vol. $\% \mathrm{~N}_{2}$ gas mixture) only after 15 hours nitriding. Increasing the nitrogen concentration to $76 \%$ vol. $\%$ $\mathrm{N}_{2}$ also could not lead to a monophasic $\varepsilon-\mathrm{Fe}_{2-3}(\mathrm{C}) \mathrm{N}$ layer. Skonieski et al. ${ }^{8}$ showed that for nitrocarburized samples with 70 vol. $\% \mathrm{~N}_{2}$ and 3 vol.\% methane $\left(\mathrm{CH}_{4}\right)$ the proportion of $\varepsilon-\mathrm{Fe}_{2-3}(\mathrm{C}) \mathrm{N}$ increased if compared to the nitrided condition with 70 vol. $\% \mathrm{~N}_{2}$ and without $\mathrm{CH}_{4}$, but the $\gamma^{\prime}-\mathrm{Fe}_{4} \mathrm{~N}$ phase was still present and, consequently, it was not possible to produce the monophasic $\varepsilon-\mathrm{Fe}_{2-3}(\mathrm{C}) \mathrm{N}$ on the surface of the samples.

For all the plasma nitrided samples with 5 vol. $\% \mathrm{~N}_{2}$, the iron peak is still seen (especially in shorter treatment times), Figure 1c, however, it is slightly shifted to the left. Peaks of $\gamma^{\prime}-\mathrm{Fe}_{4} \mathrm{~N}$ phase are also seen for this condition, this is an indication that the $\gamma^{\prime}-\mathrm{Fe}_{4} \mathrm{~N}$ began to be formed at the surface appearing as iron nitride clusters ${ }^{8}$. This analysis agrees with the fact that a really thin compound layer could have been formed even for the $3 \mathrm{~h}$ treatment. As the nitriding time increases to 6 and 9 hours, formation of $\gamma^{\prime}-\mathrm{Fe}_{4} \mathrm{~N}$ is clearly indicated by the $\gamma^{\prime}-\mathrm{Fe}_{4} \mathrm{~N}$ peaks and the very low intensity of the $\alpha$-iron peak. This analysis show that the compound layer growth is dependent on the nitriding time, once temperatures, gas mixtures and the other related variables were constant.

\subsection{Modification of surface properties after plasma nitriding}

Figures 2a-i show the optical microscopy micrographs of the cross-section for the 9 different plasma nitriding conditions. The treatments developed the formation of a compound layer in the outermost superficial part of the specimens, followed by the diffusion layer below. The thin white portion on top distinguishes the compound layer. The diffusion zone is not clearly revealed in the optical microscopy for this steel. For the composition of the gas mixture of 5 vol. $\% \mathrm{~N}_{2}$, Figures $2 \mathrm{~g}-\mathrm{i}$, the nitrided layer is composed predominantly by a diffusion zone whereas for 24 and 76 vol. $\% \mathrm{~N}_{2}$ a compound layer is clearly seen (see Figures 2a-f).

Table 2 summarizes the results regarding the optical microscopy cross-sectional analysis of the plasma nitrided samples. The compound layer thickness increases with the treatment time and with increased nitrogen concentration. A similar response is observed for the total case depths. The case depth $(C D)$, Equation 2, is directly proportional to the square root of the processing time by the layer growth constant $(k)$ 


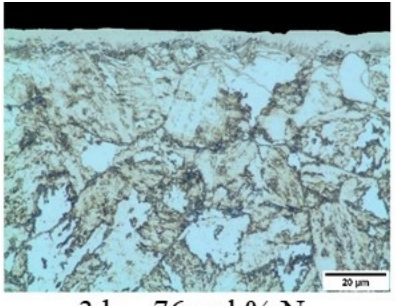

$3 \mathrm{~h}-76$ vol. $\% \mathrm{~N}_{2}$

(a)

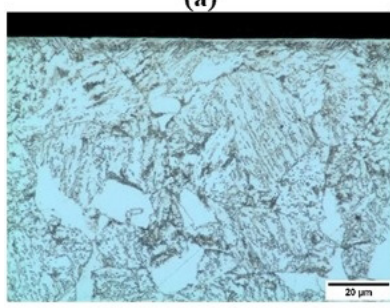

$3 \mathrm{~h}-24$ vol. $\% \mathrm{~N}_{2}$

(d)

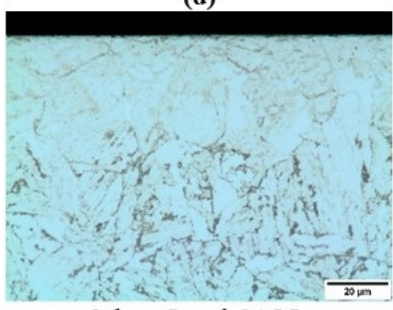

$3 \mathrm{~h}-5$ vol. $\% \mathrm{~N}_{2}$

(g)

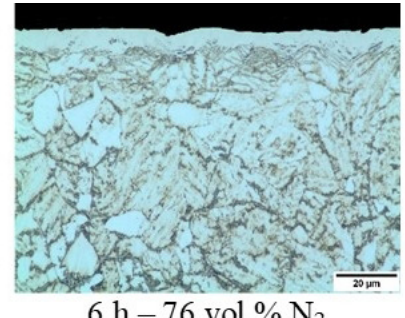

(b)

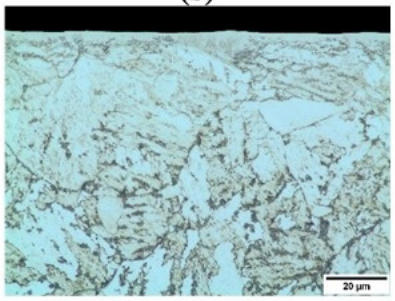

$6 \mathrm{~h}-24$ vol. $\% \mathrm{~N}_{2}$

(e)

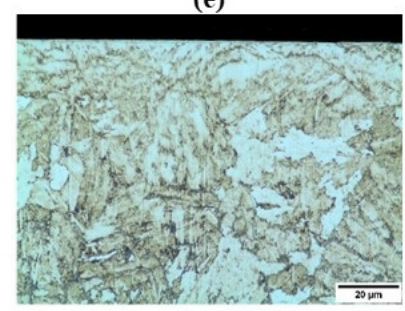

$6 \mathrm{~h}-5$ vol. $\% \mathrm{~N}_{2}$

(h)

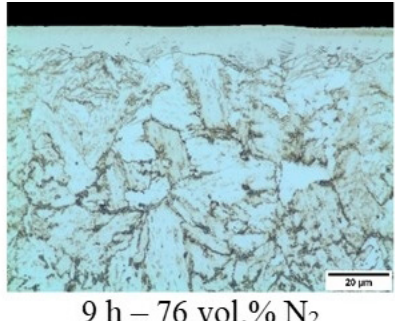

(c)

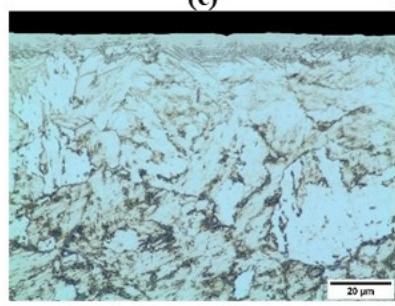

$9 \mathrm{~h}-24$ vol. $\% \mathrm{~N}_{2}$

(f)

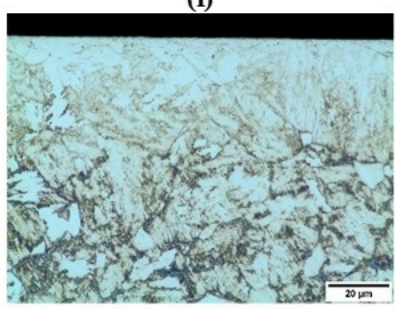

$9 \mathrm{~h}-5 \mathrm{vol} . \% \mathrm{~N}_{2}$

(i)

Figure 2. Optical micrographs showing the cross-sectional microstructure for processing temperature of $500{ }^{\circ} \mathrm{C}$ and three different gas mixtures: (a-c) 76 vol. \% $\mathrm{N}_{2}$; (d-f) 24 vol. $\% \mathrm{~N}_{2}$; (g-i) 5 vol. $\% \mathrm{~N}_{2}$. For each temperature, the times are (a, d, g) $3 \mathrm{~h},(\mathrm{~b}, \mathrm{e}, \mathrm{h}) 6 \mathrm{~h}$ and (c, f, i) $9 \mathrm{~h}$.

Table 2. Modification of surface properties after plasma nitriding with three different nitrogen gas composition.

\begin{tabular}{|c|c|c|c|c|}
\hline Nitriding parameters & $\begin{array}{c}\text { Compound layer } \\
\text { thickness }(\mu \mathrm{m})\end{array}$ & Case depth $(\mu \mathrm{m})$ & $\begin{array}{l}\text { Layer growth constant } \\
(\mathrm{k}) \text {, for } 500^{\circ} \mathrm{C}\end{array}$ & $\begin{array}{c}\text { Surface hardness } \\
\left(\mathbf{H V}_{0,1}\right)\end{array}$ \\
\hline $3 \mathrm{~h}-76$ vol. $\% \mathrm{~N}_{2}$ & $4.3 \pm 0.2$ & $139.2 \pm 30.3$ & \multirow{3}{*}{80.5} & $1246.2 \pm 95.5$ \\
\hline $6 \mathrm{~h}-76$ vol. $\% \mathrm{~N}_{2}$ & $6.7 \pm 0.3$ & $192.4 \pm 24.9$ & & $1294.8 \pm 107.8$ \\
\hline $9 \mathrm{~h}-76$ vol. $\% \mathrm{~N}_{2}$ & $8.2 \pm 0.2$ & $245.4 \pm 40.3$ & & $1079.2 \pm 86.7$ \\
\hline $3 \mathrm{~h}-24$ vol. $\% \mathrm{~N}_{2}$ & $2.1 \pm 0.4$ & $120.3 \pm 25.1$ & \multirow{3}{*}{73.6} & $914.3 \pm 47.8$ \\
\hline $6 \mathrm{~h}-24$ vol. $\% \mathrm{~N}_{2}$ & $3.1 \pm 0.3$ & $175.0 \pm 32.6$ & & $929.0 \pm 53.9$ \\
\hline $9 \mathrm{~h}-24$ vol. $\% \mathrm{~N}_{2}$ & $3.9 \pm 0.2$ & $223.3 \pm 27.5$ & & $1078.1 \pm 54.9$ \\
\hline $3 \mathrm{~h}-5$ vol. $\% \mathrm{~N}_{2}$ & $0.2 \pm 0.2$ & $117.6 \pm 27.2$ & \multirow{3}{*}{58.4} & $970.0 \pm 110.1$ \\
\hline $6 \mathrm{~h}-5$ vol. $\% \mathrm{~N}_{2}$ & $0.5 \pm 0.3$ & $134.3 \pm 25.2$ & & $912.2 \pm 60.9$ \\
\hline $9 \mathrm{~h}-5$ vol. $\% \mathrm{~N}_{2}$ & $0.7 \pm 0.3$ & $172.7 \pm 22.4$ & & $853.9 \pm 94.2$ \\
\hline
\end{tabular}

which includes the variables temperature, chemical composition of the steel and concentration gradient of a given hardening species. In terms of temperature, the layer growth constant increases exponentially as a function of absolute temperature. This allows diffusional processes to be considered thermally activated $^{26}$. Sun; Bell ${ }^{4}$ showed that, under constant temperature conditions, there is a potential limit for the formation of the compound layer that depends on the nitrogen fraction in the gas mixture and the nitriding time. Below this potential limit, only the formation of the diffusion zone occurs.

$C D=k \cdot \sqrt{\text { time }}$
In terms of the total case depth (see Table 2), conditions with nitrogen gas rich composition ( $\left.76 \mathrm{vol} . \% \mathrm{~N}_{2}\right)$ developed the deepest nitrided case of all evaluated treatment conditions (see Figure 3a). On the other hand, the reduction of nitrogen composition ( 24 and 5 vol. $\% \mathrm{~N}_{2}$ ) in the nitriding atmosphere led to shallower nitrided cases (see Figures $3 \mathrm{a}, \mathrm{b}$ ). When comparisons are done between these three nitriding conditions, 76,24 and $5 \mathrm{vol} . \% \mathrm{~N}_{2}$, in terms of total layer depth, as well as in terms of surface hardness, the behavior is as expected, the higher the $\mathrm{N}_{2}$ content in the gas mixture the higher the total layer depth and surface hardness of the nitrided layers.

The choice of the nitriding parameters has a significant influence on the hardness profile in the near surface regions ${ }^{8,16,17,27}$. 


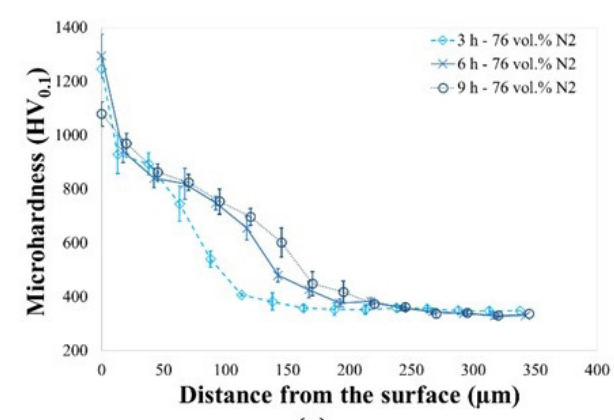

(a)

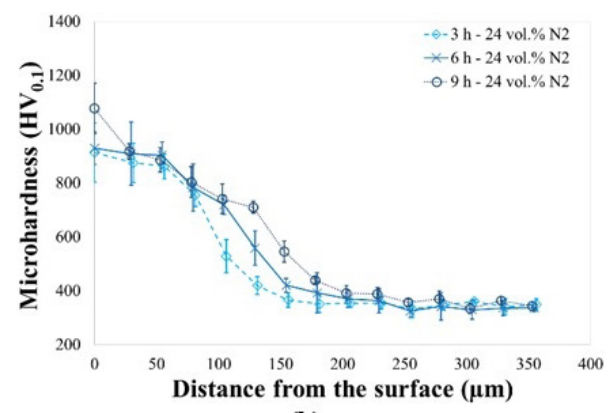

(b)

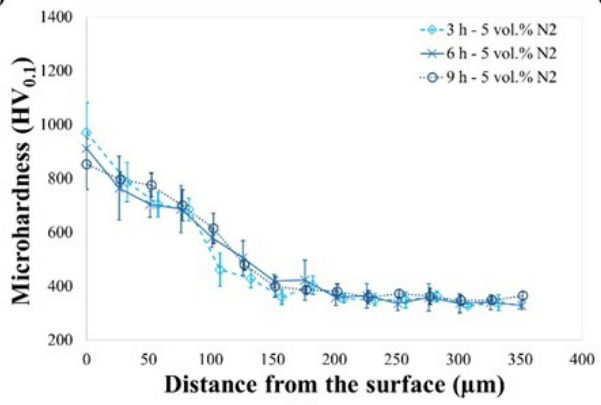

(c)

Figure 3. Microhardness profiles of plasma nitrided samples for (a) 76 vol. $\% \mathrm{~N}_{2}$, (b) 24 vol. $\% \mathrm{~N}_{2}$ and (c) 5 vol. $\% \mathrm{~N}_{2}$.

Figures 3a-c shows microhardness profiles of the plasma nitrided samples at $500{ }^{\circ} \mathrm{C}$ with a function of treatment time and nitrogen gas composition. The hardness decreases from surface to core, since the concentration of metal nitrides decreases towards core ${ }^{17}$. The surface hardness of the plasma nitrided layer is approximately three times higher than that of the non-nitrided surface. The plasma nitriding (greater surface hardness among the investigated group) increases the surface hardness by about 392.4\% (1294.8 $\left.\mathrm{HV}_{0.1}\right)$ for plasma nitrided samples for $6 \mathrm{~h}$ with 76 vol. $\% \mathrm{~N}_{2}, 326.7 \%$ $\left(1078.1 \mathrm{HV}_{0.1}\right)$ for plasma nitrided for $9 \mathrm{~h}$ with $24 \mathrm{vol} . \% \mathrm{~N}_{2}$ and up to $294.0 \%\left(970.0 \mathrm{HV}_{0.1}\right)$ for plasma nitrided samples for $3 \mathrm{~h}$ with 5 vol. $\% \mathrm{~N}_{2}$. It can be seen Figures $3 \mathrm{a}$-c that the hardness of the diffusion layer increases with increasing treatment time, as shown by Lee; Park ${ }^{27}$.

The case depth increases with increasing time, temperature and nitrogen concentration as expected for diffusion-controlled growth ${ }^{16,17}$. On the other hand, Alsaran et al. ${ }^{17}$ had previously tried to explain the increase in the depth of the nitrided layer by increasing the ratio of hydrogen to nitrogen. Alsaran's proposal seems to make sense with this work with regard to the average voltage of the processes in relation to the proportion of hydrogen in the atmosphere, which was higher for higher hydrogen ratios. However, the effectiveness of this supposedly higher nitrogen dissociation was not verified in the present study to the point of promoting microhardness profiles with higher values for gas proportions with less nitrogen.

\subsection{Nitrogen concentration and carbon composition}

Figures $4 \mathrm{a}, \mathrm{b}$ shows the typical nitrogen concentration profiles and carbon composition of plasma nitrided DIN $18 \mathrm{MnCrSiMo6}-4$ steel. The increase in the nitrogen content is evident with the treatment time. As a result of nitrogen uptake in the nitrided case, a decarburized zone near the surface and a carbon-rich zone in the nitriding front have been developed (see Figure 4b). Tier et al. ${ }^{28}$ say that during nitriding, alloy carbides especially chromium carbides are make unstable in the nitrided layer. Hence, nitrogen replaces carbon in the carbide structure ${ }^{1,29}$. Consequently, carbon is released and diffuses in both directions, i.e. to the surface and to the steel core.

The carbon content profile has a characteristic shape, due to the formation of the compound layer in the surface, high content of nitrogen is seen and the carbon content is low, then as the distance from the surface increases, the carbon concentration becomes higher, forming a maximum located in the interface region between the compound layer and the diffusion zone. Several other authors ${ }^{3,4,6,8,29}$ discussed the redistribution of carbon in the near-surface region of plasma nitrided steels. This carbon peak concentration below the compound layer would be related to the formation of cementite, like precipitates in the grain boundaries ${ }^{3,29}$, which leads to lower toughness of the nitrided layer ${ }^{1}$.

\subsection{Fracture toughness}

Regarding an expected decrease in toughness as surface hardness increases, fracture toughness tests were performed based on the method presented by Nolan et al. ${ }^{5}$, to induce the formation of measurable Palmqvist cracks (an example is presented in Figure 5a. Due to reasons previously reported and the fact that this fracture toughness test is not yet fully established for nitrided layers, the load failure criterion was adopted as the load at which it was possible to verify by optical microscopy the beginning of cracking around the indentation. An example concentric cracking is shown in Figure $5 b$. 


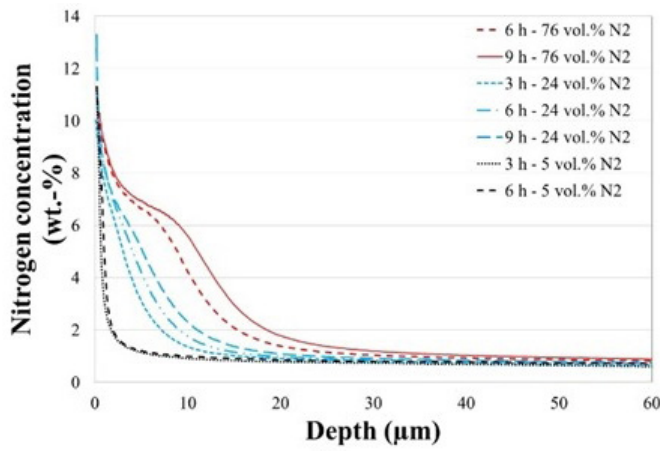

(a)

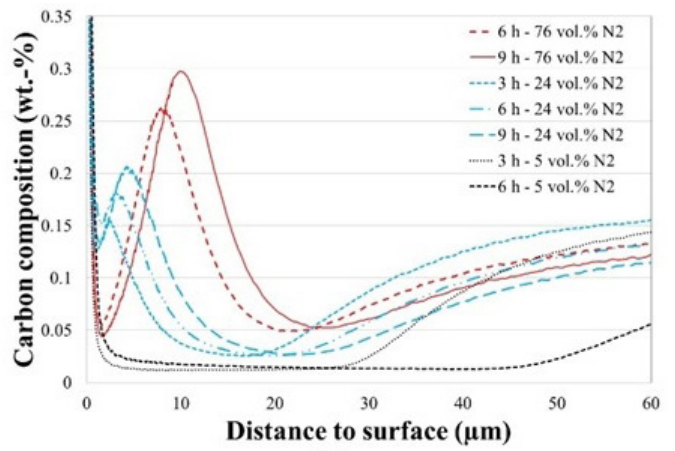

(b)

Figure 4. Profile of chemical composition after plasma nitriding: (a) Nitrogen concentration depth profiles for the plasma nitrided samples, (b) Carbon composition for the plasma nitrided samples.

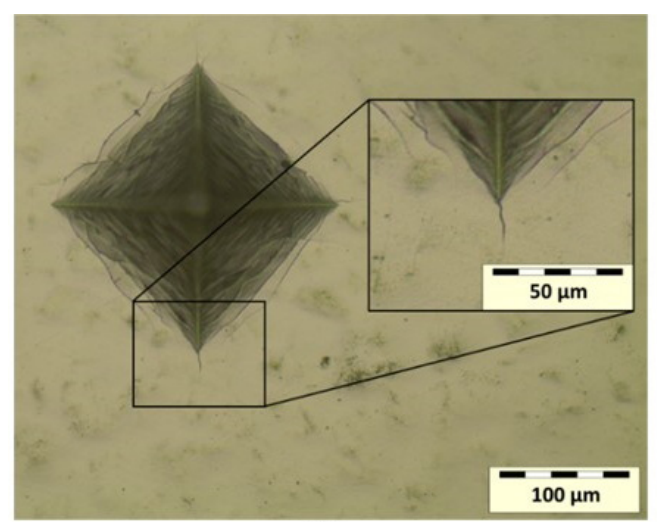

(a)

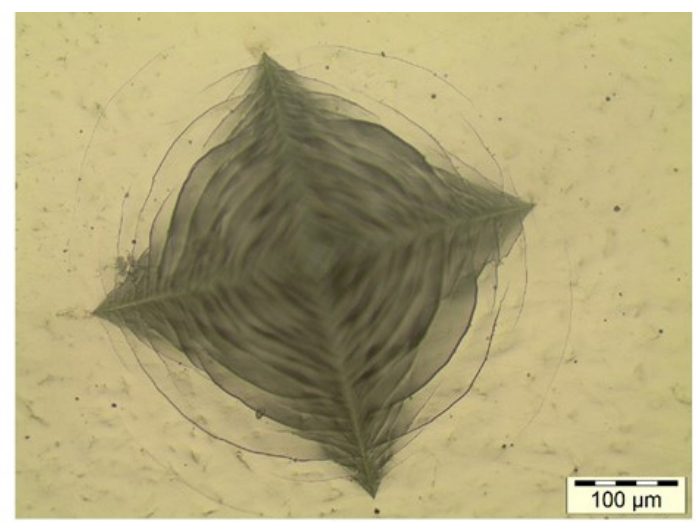

(b)

Figure 5. Representative images of the fracture toughness tests: (a) Palmqvist cracks of plasma nitrided sample for $6 \mathrm{~h}$ with 76 vol.\% $\mathrm{N}_{2}$. Indentation load of $20 \mathrm{kgf}$; (b) concentric ring cracks of plasma nitrided sample for $3 \mathrm{~h}$ with $76 \mathrm{vol} \% \mathrm{~N}_{2}$. Indentation load of $50 \mathrm{kgf}$.

The predominant mode of cracking for these cases was concentric rings, becoming more evident and more extensive with higher loads. Palmqvist cracks are clearly developed for nitrided samples with different nitrogen gas composition, however, the appearance of concentric cracking also became apparent, becoming more significant with increasing load. The reason for this is not immediately apparent, although probably related to the increased thickness of the compound layer ${ }^{16}$. As the compound layer thickness decreases and/or the indentation depth increases (also by increasing load), the indentation effects are not restricted to the compound layer, and plastic deformation in the diffusion zone will occur, since the diffusion zone is much more ductile than the compound layer. Then in these cases, there is a load bearing capacity failure for the compound layer, appearing the concentric cracks around the indentations. On the other hand, for thicker compound layers and/or lower loads the indentation effects are restricted to the compound layer, without plastic deformation in the diffusion zone, which leads to the typical Palmqvist.

The calculated fracture toughness $\left(\mathrm{K}_{\mathrm{IC}}\right)$ for each condition is shown in Figures 6a-c. Where a condition showed no Palmqvist cracking, a value of zero is presented for $\mathrm{K}_{\mathrm{IC}}$. In the case of nitrided samples with 76 vol. $\% \mathrm{~N}_{2}$, it may be possible to extrapolate a value for $\mathrm{K}_{\mathrm{IC} 0}$ in order of 5.2-5.9 MN/m $\mathrm{m}^{3 / 2}$ (see Figure 6a). For plasma nitrided samples with 24 vol. $\% \mathrm{~N}_{2}$, there is a clear trend of fracture toughness data, which enables extrapolation to a $\mathrm{K}_{\mathrm{IC} 0}$ value of 7.6-10.2 MN/m $\mathrm{m}^{3 / 2}$ (see Figure 6b). Although the plasma nitrided samples with 5 vol. $\% \mathrm{~N}_{2}$ have thinner case layers, it was possible to estimate to a $\mathrm{K}_{\mathrm{IC} 0}$ value of $\sim 6.4-16.3 \mathrm{MN} /$ $\mathrm{m}^{3 / 2}$ (see Figure 6c).

Plasma nitriding leads to an increase in hardness on the surface, for the reason it also ends up creating a less ductile region more prone to brittle fracture. The mechanical properties of the diffusion zone influence the fracture properties of the compound layer, since the diffusion zone provides support for the surface compound layer. In general, increased nitriding time seems to result in increased fracture toughness for samples where there is consistent thickness of the compound layer ${ }^{16}$. This would also support the proposition that a harder substrate actually results in an increase in fracture toughness measurement through improved mechanical support (load bearing capacity) of the compound layer by the diffusion zone. Although the average concentric rings indicate detachment of the compound layer due to the crack initiation below this. However, cracks originated on the compound layer can also be harmful, especially in components that support high loads and alternate loading, as they can represent the onset of a fatigue failure, for example. Attention must be paid to the fact that the transition from Palmqvist cracks to medium concentric cracking may determine the onset of cracks in the diffusion zone and/or in material's core. 


\subsection{Residual stress analysis}

Figures 7a-c show residual stress depth profiles in the diffusion zone for the different plasma nitriding conditions. Compressive residual stresses found in the diffusion zone are the result of structural misfits caused by the precipitation of alloy nitrides and carbonitrides in the iron matrix ${ }^{1,30}$. For all nitriding treatment parameters, residual stresses were found to be compressive in the diffusion zone. Compressive residual stresses decrease with depth before approaching tensile values at the case/core microstructure transition, as typically reported in different articles ${ }^{1,16,31}$. But this transition is not seen in the depth profiles as corrections for residual stress relaxation after eletroposlishing steps was not carried

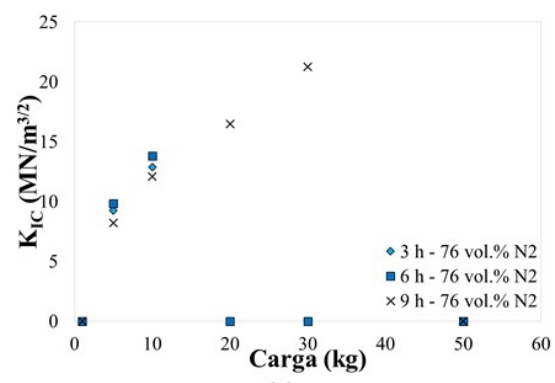

(a)

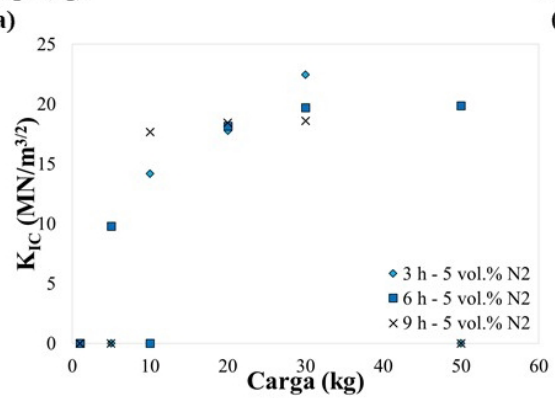

(c)

Figure 6. $\mathrm{K}_{\mathrm{IC}}$ calculated for the plasma nitrided samples for (a) 76 vol. $\% \mathrm{~N}_{2}$, (b) 24 vol.\% $\mathrm{N}_{2}$ and (c) 5 vol. $\% \mathrm{~N}_{2}$.

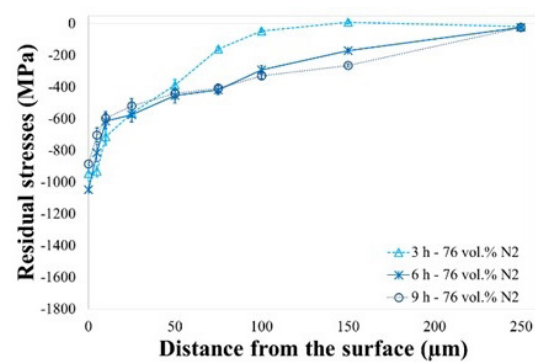

(a) out. However, the error is relatively small for the measured values, especially close to the surface.

In the case of plasma nitriding with $76 \mathrm{vol} . \% \mathrm{~N}_{2}$, maximum compressive residual stresses of 885.2-1047.0 MPa were measured on the surface, depending on the treatment time (Figure 7a). Decreasing the $\mathrm{N}_{2}$ content in the treatment gas mixture to 24 vol.\% (Figure $7 \mathrm{~b}$ ) led to lower compressive residual stresses at the surface, resulting in compressive residual stress maximum of $773.0 \mathrm{MPa}$. The same is true for plasma nitriding with $5 \mathrm{vol} . \% \mathrm{~N}_{2}$, where depending on the nitriding time maximum compressive residual stresses in the range of 692.2 to $757.7 \mathrm{MPa}$ (see Figure 7c) are measured on the surface. As in the case of nitriding time, increase in nitrogen gas composition results in higher compressive residual stresses and deeper maximum stress location.

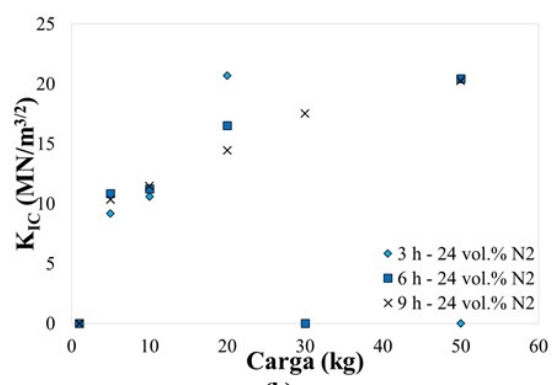

(b)

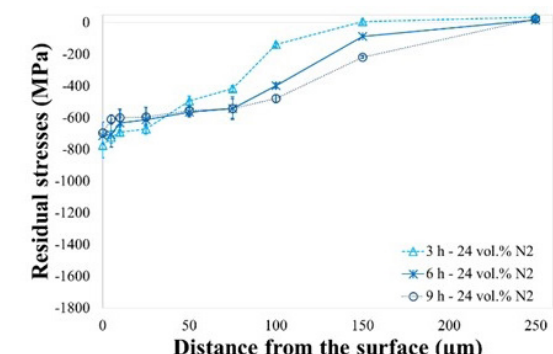

(b)

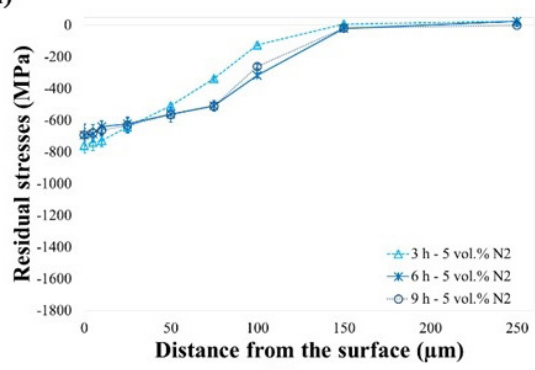

(c)

Figure 7. Residual stress depth profiles for plasma nitrided samples for (a) 76 vol. $\% \mathrm{~N}_{2}$, (b) 24 vol. $\% \mathrm{~N}_{2}$ and (c) 5 vol. $\% \mathrm{~N}_{2}$. 


\subsection{Final discussion}

One of the main applications of plasma nitriding, is the improvement of surface properties. Using the example of gear flanks, by increasing the surface hardness and providing significant improvements in the resistance and increase in the contact fatigue resistance will be achieved. In this case, the case depth should be at least $0.3 \mathrm{~mm}$, and therefore, will be needed longer nitriding times. In order to estimate the treatment time adequate to produce sufficient case depth for the gears and other components subjected to contact fatigue, the layer growth constant $(\mathrm{k})$ was calculated (see Table 2). The compilation of compound layer thicknesses, case depth, surface hardness, fracture toughness estimate $\left(\mathrm{K}_{\mathrm{ICO}}\right)$ and maximum residual stresses of the diffusion zone for the different plasma nitriding conditions investigated in this paper are shown in Table 3.

Plasma nitriding with three different gas mixtures and treatment times produced the formation of a compound layer in the outermost superficial part of the samples. Longer nitriding times and nitrogen rich gas composition led to greater diffusion zone depth and thicker compound layer (see Table 3). It is possible to see that both nitriding conditions, with higher concentrations of nitrogen ( 76 and 24 vol. $\% \mathrm{~N}_{2}$ ), have invariably generated the characteristic phases $\varepsilon-\mathrm{Fe}_{2-3}(\mathrm{C})$ $\mathrm{N}$ and $\gamma^{\prime}-\mathrm{Fe}_{4} \mathrm{~N}$, with major $\varepsilon-\mathrm{Fe}_{2-3}(\mathrm{C}) \mathrm{N}$ content for the 76 vol. $\% \mathrm{~N}_{2}$ condition. Peaks of iron and $\gamma^{\prime}-\mathrm{Fe}_{4} \mathrm{~N}$ phase are seen for all plasma nitrided samples with 5 vol. $\% \mathrm{~N}_{2}$.

It might normally be expected that the $\varepsilon-\mathrm{Fe}_{2-3}(\mathrm{C}) \mathrm{N}$ containing compound layer would be harder than the $\gamma^{\prime}-\mathrm{Fe}_{4} \mathrm{~N}$ layer on the plasma nitrided samples. However, it was shown in the work of Nolan et al. ${ }^{5}$ that the hardness lowering observed may be a result of very fine closed porosity apparent in the mixed phase compound layer. This porosity, and the fact that the structure is multiphase, may lead to lower fracture toughness values. It is also likely that the mechanical properties of the diffusion layer will influence the fracture properties of the surface layers, since the diffusion layer provides mechanical support for the surface layers 5 . For example, the Palmqvist cracking appears to become more consistent with increasing nitrogen gas composition and processing time for the samples. The reason for this is not immediately apparent, though it is most likely related to the increased thickness of the compound layer and subsequent enhancement of the brittle fracture behavior of the surface.

Increasing the nitriding gas mixture from 5 vol. $\% \mathrm{~N}_{2}$ to 76 vol. $\% \mathrm{~N}_{2}$ increased the maximum Vickers hardness from 970.0 to $1246.2 \mathrm{HV}_{0.1}$ (for plasma nitrided samples for $3 \mathrm{~h}$ ), but comparing the samples with different nitriding times, the residual compressive stresses tend to decrease with the increase in time (see Table 3). According to Sun; Bell' ${ }^{4}$, this arises from the fact that hardness increase is more directly related to nitrogen uptake and nitride precipitation, whilst residual stress generation is not only related to these but also related to carbon redistribution, carbide dissolution and formation of grain boundary phases in the nitrided case.

Residual stresses are an important factor influencing both fatigue and wear. It is well recognized, that introducing compressive residual stresses results in improvements of fatigue life. The literature presents that a though deep diffusion zone can provide both higher hardness and load bearing capacity, suitable for posterior thin film hard coating deposited on the surface ${ }^{3,29}$. Although the nitrogen rich gas composition lead to higher surface compressive residual stresses (above 885.2 MPa) for all nitriding times, the best combination will depend on the application. As for example in nitriding of gears, the analysis must consider the gear tooth flank hertezian stresses and gear tooth root bending stresses. Besides that, too high compressive residual stresses in the interface between diffusion zone and compound layer can lead to premature surface spalling.

\section{Conclusions}

- The results presented in this investigation have shown that by varying nitrogen gas composition is possible to obtain compound layers for an DIN 18MnCrSiMo6-4 steel with significant different microstructural and mechanical properties;

- The nitrogen concentration profiles of the plasma nitrided samples show a maximum nitrogen concentration close to the surface, which gradually decays with depth. In addition, it is evident that the nitrogen percentage as a function of depth decreases more abruptly in plasma nitrided samples in a shorter treatment time;

Table 3. Compilation of results from compound layer thickness, case depth, surface hardness, fracture toughness estimate $\left(\mathrm{K}_{\mathrm{IC} 0}\right)$ and maximum residual stresses of the diffusion zone.

\begin{tabular}{|c|c|c|c|c|c|}
\hline Nitriding parameters & $\begin{array}{l}\text { Compound layer } \\
\text { thickness }(\mu \mathrm{m})\end{array}$ & Case depth $(\mu \mathrm{m})$ & $\begin{array}{c}\text { Surface hardness } \\
\left(\mathrm{HV}_{0.1}\right)\end{array}$ & $\begin{array}{c}\mathrm{K}_{\mathrm{IC0}} \text { estimate } \\
\left(\mathrm{MN} / \mathrm{m}^{3 / 2}\right)\end{array}$ & $\begin{array}{c}\text { Maximum } \\
\text { residual stress } \\
(\mathrm{MPa})\end{array}$ \\
\hline $3 \mathrm{~h}-76$ vol. $\% \mathrm{~N}_{2}$ & $4.3 \pm 0.2$ & $139.2 \pm 30.3$ & $1246.2 \pm 95.5$ & 5.6 & $-945.9 \pm 50.0$ \\
\hline $6 \mathrm{~h}-76$ vol. $\% \mathrm{~N}_{2}$ & $6.7 \pm 0.3$ & $192.4 \pm 24.9$ & $1294.8 \pm 107.8$ & 5.9 & $-1047.0 \pm 16.5$ \\
\hline $9 \mathrm{~h}-76$ vol. $\% \mathrm{~N}_{2}$ & $8.2 \pm 0.2$ & $245.4 \pm 40.3$ & $1079.2 \pm 86.7$ & 5.2 & $-885.2 \pm 8.1$ \\
\hline $3 \mathrm{~h}-24$ vol. $\% \mathrm{~N}_{2}$ & $2.1 \pm 0.4$ & $120.3 \pm 25.1$ & $914.3 \pm 47.8$ & 10.2 & $-773.0 \pm 80.4$ \\
\hline $6 \mathrm{~h}-24$ vol. $\% \mathrm{~N}_{2}$ & $3.1 \pm 0.3$ & $175.0 \pm 32.6$ & $929.0 \pm 53.9$ & 7.7 & $-712.8 \pm 84.4$ \\
\hline $9 \mathrm{~h}-24$ vol. $\% \mathrm{~N}_{2}$ & $3.9 \pm 0.2$ & $223.3 \pm 27.5$ & $1078.1 \pm 54.9$ & 8.2 & $-694.5 \pm 67.8$ \\
\hline $3 \mathrm{~h}-5$ vol. $\% \mathrm{~N}_{2}$ & $0.2 \pm 0.2$ & $117.6 \pm 27.2$ & $970.0 \pm 110.1$ & 11.7 & $-757.7 \pm 47.4$ \\
\hline $6 \mathrm{~h}-5$ vol. $\% \mathrm{~N}_{2}$ & $0.5 \pm 0.3$ & $134.3 \pm 25.2$ & $912.2 \pm 60.9$ & 6.4 & $-692.2 \pm 38.8$ \\
\hline $9 \mathrm{~h}-5$ vol. $\% \mathrm{~N}_{2}$ & $0.7 \pm 0.3$ & $172.7 \pm 22.4$ & $853.9 \pm 94.2$ & 16.3 & $-692.2 \pm 67.4$ \\
\hline
\end{tabular}


- The tested nitriding conditions with a low amount of $\mathrm{N}_{2}(5 \mathrm{vol} . \%)$ led to nitriding layers predominantly with diffusion zone and by increasing the time with a monophasic $\gamma^{\prime}-\mathrm{Fe}_{4} \mathrm{~N}$ compound layer. By increasing the amount of nitrogen, to an intermediate level, as 24 vol. $\% \mathrm{~N}_{2}$, then a relatively thick compound layer of $\varepsilon-\mathrm{Fe}_{2-3}(\mathrm{C}) \mathrm{N}$ and $\gamma$ '- $\mathrm{Fe}_{4} \mathrm{~N}$ nitrides is formed, but with still higher amounts of $\varepsilon-\mathrm{Fe}_{2-3}(\mathrm{C}) \mathrm{N}$ than $\gamma^{\prime}-\mathrm{Fe}_{4} \mathrm{~N}$. Nitrogen concentrations of 76 vol. $\%$ took to an increase of compound layer hardness and amount of $\varepsilon-\mathrm{Fe}_{2-3}(\mathrm{C}) \mathrm{N}$ nitrides;

- In order to estimate the treatment time adequate to produce sufficient case depth for the gears and other components subjected to contact fatigue, the layer growth constant $(\mathrm{k})$ based on the results presented was calculated;

- $\quad$ Plasma nitriding of DIN 18MnCrSiMo6-4 steel increases the surface hardness by about $392.4 \%$ (1294.8 $\mathrm{HV}_{0.1}$ ) for plasma nitrided samples for $6 \mathrm{~h}$ with 76 vol. $\% \mathrm{~N}_{2}, 326.7 \%\left(1078.1 \mathrm{HV}_{0.1}\right)$ for plasma nitrided for $9 \mathrm{~h}$ with 24 vol. $\% \mathrm{~N}_{2}$ and up to $294.0 \%\left(970.0 \mathrm{HV}_{0.1}\right)$ for plasma nitrided samples for $3 \mathrm{~h}$ with 5 vol. $\% \mathrm{~N}_{2}$;

- A linear relationship was obtained between fracture toughness on DIN 18MnCrSiMo6-4 steel and case depth. The Palmqvist cracking appears to become more consistent with increasing nitrogen gas composition and processing time for the samples. The reason for this is not immediately apparent, though it is most likely related to the increased thickness of the compound layer and subsequent enhancement of the brittle fracture behavior of the surface;

- The diffusion zone of the different plasma nitrided conditions presented compressive residual stresses. In general, higher nitriding time and nitrogen rich gas composition led to deeper nitride layers with compressive residual stresses up to the end of the layers in core direction.

\section{Acknowledgments}

This work was carried out with the support of CAPES BRAGECRIM PROGRAM (Process no. 88881.142485/201701 - aid number 1844/2017); CAPES - PROEX (Process 23038.000341/2019-71) and CNPq (Grant 308773/2018-7).

\section{References}

1. Rocha AS, Strohaecker T, Tomala V, Hirsch T. Microstructure and residual stresses of a plasma-nitrided M2 tool steel. Surf Coat Tech. 1999;115(1):24-31. http://dx.doi.org/10.1016/ S0257-8972(99)00063-8.

2. Podgornik B, Leskovsek V, Kovacic M, Vizintin J. Analysis and prediction of residual stresses in nitrided tool steel. Mater Sci Forum. 2011;681:352-7. http://dx.doi.org/10.4028/www. scientific.net/MSF.681.352.

3. Rocha AS, Strohaecker T, Hirsch T. Effect of different surface states before plasma nitriding on properties and machining behavior of M2 high-speed steel. Surf Coat Tech. 2003;165(2):176-85. http://dx.doi.org/10.1016/S0257-8972(02)00768-5.
4. Sun Y, Bell T. Plasma surface engineering of low alloy steel. Mater Sci Eng A. 1991;140:419-34. http://dx.doi.org/10.1016/09215093(91)90458-Y.

5. Nolan D, Leskovsek V, Jenko M. Estimation of fracture toughness of nitride compound layer on tool steel by application of the Vickers indentation method. Surf Coat Tech. 2006;201(12):182-8. http://dx.doi.org/10.1016/j.surfcoat.2005.11.077.

6. Both GB, Rocha AS, Santos GR, Hirsch TK. An investigation on the suitability of different surface treatments applied to a DIN X100CrMoV8-1-1 for cold forming applications. Surf Coat Tech. 2014;244:142-50. http://dx.doi.org/10.1016/j. surfcoat.2014.01.060.

7. Akbari A, Mohammadzadeh R, Templier C, Riviere JP. Effect of the initial microstructure on the plasma nitriding behavior of AISI M2 high speed steel. Surf Coat Tech. 2010;204(24):411420. http://dx.doi.org/10.1016/j.surfcoat.2010.05.042.

8. Skonieski AFO, Santos GR, Hirsch TK, Rocha AS. Metallurgical response of an AISI 4140 steel to different plasma nitriding gas mixtures. Mater Res. 2013;16(4):884-90. http://dx.doi. org/10.1590/S1516-14392013005000073.

9. Hasler S, Roelofs H, Lembke M, Caballero FG. New air cooled steels with outstanding impact toughness. In: 3nd International Conference on Steels in Cars and Trucks; 2011 June; Salzburg. Proceedings. Düsseldorf: Stahleisen; 2011.

10. Keul C, Wirths V, Bleck W. New bainitic steel for forgings. Arch Civ Mech Eng. 2012;12(2):119-25. http://dx.doi.org/10.1016/j. acme.2012.04.012.

11. Raedt H, Speckenheuer U, Vollrath K. New forged steels: energy-efficient solutions for stronger parts. ATZ Autotechnology. 2012;12(1):12-7. http://dx.doi.org/10.1365/s35595-012-0089-9.

12. Buchmayr B. Critical assessment 22: bainitic forging steels. Mater Sci Technol. 2016;32(6):517-22. http://dx.doi.org/10.1 080/02670836.2015.1114272.

13. Roelofs H, Hasler S, Urlau U, Lembke MI, Olschewski G. Continuously cooled bainitic steel HSX®Z12: one decade of experience. In: 4th International Conference on Steels in Cars and Trucks; 2014 June; Braunschweig, Germany. Proceedings. Düsseldorf: Stahleisen; 2014.

14. Lembke MI, Olschewski G, Roelofs H, Klümper-Westkamp H. Nitrieren von hochfesten, bainitischen langprodukten. Journal of Heat Treatment and Materials. 2014;69(3):195-200. http:// dx.doi.org/10.3139/105.110226.

15. Abdalla AJ, Santos D, Vasconcelos G, Baggio-Scheid VH, Silva DF. Changing in fatigue life of $300 \mathrm{M}$ bainitic steel after laser carburizing and plasma nitriding. MATEC Web of Conferences. 2018;165:21002. http://dx.doi.org/10.1051/ matecconf/201816521002.

16. Dalcin RL, Oliveira LF, Diehl IL, Dias VW, Rocha AS. Response of a DIN 18MnCrSiMo6-4 continuous cooling bainitic steel to plasma nitriding with a nitrogen rich gas composition. Mater Res. 2020;23(2):1-9. http://dx.doi.org/10.1590/1980-5373mr-2020-0036.

17. Alsaran A, Karakan M, Çelik A. The investigation of mechanical properties of ion-nitrided AISI 5140 low-alloy steel. Mater Charact. 2002;48(4):323-7. http://dx.doi.org/10.1016/S10445803(02)00275-9.

18. American Society for Testing and Materials - ASTM. ASTM E92: standard test methods for Vickers hardness and Knoop hardness of metallic materials. West Conshohocken: ASTM International; 2017.

19. Deutsches Institut für Normung - DIN. DIN 50 190: härtetiefe wärmebehandelter tiele: ermittlung der nitrierhärtetiefe: teil 3. Berlin: DIN; 1979.

20. Shetty DK, Wright IG, Mincer PN, Clauer AH. Indentation fracture of WC-Co cermets. J Mater Sci. 1985;20(5):1873-82. http://dx.doi.org/10.1007/BF00555296.

21. Gong W, Tomota Y, Harjo S, Su YH, Aizawa K. Effect of prior martensite on bainite transformation in nanobainite 
steel. Acta Mater. 2015;85:243-9. http://dx.doi.org/10.1016/j. actamat.2014.11.029.

22. Davis JR. Gear materials, properties, and manufacture. Materials Park: ASM International; 2005. 339 p.

23. Rakhit AK. Heat treatment of gears: a practical guide to engineers. Materials Park: ASM International; 2000. 209 p.

24. Rolinski E. Deep nitriding for gear applications and their partial treatments: plasma/ion nitriding meets demanding gear applications by increase load capacity of gears and increased fatigue strength of components as well as less complicated masking treatments. Gears Solutions; 27 may 2016.

25. Corengia P, Ybarra G, Moina C, Cabo A, Broitman E. Microstructural and topographical studies of DC-pulsed plasma nitrided AISI 4140 low-alloy steel. Surf Coat Tech. 2005;200(7):2391-7. http://dx.doi.org/10.1016/j.surfcoat.2005.01.060.

26. Lampman S. Introduction to surface hardening of steels. In: ASM International, editor. Metals handbook: heat treating (Vol. 4, pp. 259-267). Utah: International Library Service; 1991.

27. Lee I, Park I. Microstructure and mechanical properties of surface-hardened layer produced on SKD 61 steel by plasma radical nitriding. Mater Sci Eng A. 2007;449-451:890-3. http:// dx.doi.org/10.1016/j.msea.2006.02.412.

28. Tier M, Santos AV, Kuhnen CA, Strohaecker TR, Krause JC. A study of grain boundary precipitation during plasma nitriding of steel. In: 15th Surface Modification Technologies; 2001; Indianapolis, USA. Proceedings. Materials Park: ASM Internationa; 2001.

29. Kwietniewski C, Fontana W, Moraes C, Rocha AS, Hirsch T, Reguly A. Nitrided layer embrittlement due to edge effect on duplex treated AISI M2 high-speed steel. Surf Coat Tech. 2004;179(1):27-32. http://dx.doi.org/10.1016/S02578972(03)00795-3.

30. Oettel H, Schreiber G. Formation of residual stresses in the diffusion layer: nitriren und nitrocarburieren. Wiesbaden: AWT Tagungsband; 1991. p. 139.

31. Leskovsek V, Podgornik B, Nolan D. Modelling of residual stress profiles in plasma nitrided tool steel. Mater Charact. 2008;59(4):454-61. http://dx.doi.org/10.1016/j.matchar.2007.03.009. 